\title{
Comparison between doppler derived strain and strain rate imaging and cardiac magnetic resonance in assessing right ventricular function late after repaired tetralogy of fallot
}

Majid Kyavar*, Anita Sadeghpour, Shabnam Madadi, Leili Ebrahimi, Zahra Khajali, Zahra Alizadeh, Pedram Golnari

From 2011 SCMR/Euro CMR Joint Scientific Sessions

Nice, France. 3-6 February 2011

\section{Introduction}

Evaluation of right ventricular function is still technically challenging because of the complex anatomy of the RV. CMR has been used as the gold standard for quantitative assessment of RV function, but it is not used routinely in clinical settings since it is expensive and sometimes contraindicated

\section{Purpose}

We sought to evaluate right ventricular (RV) function by Cardiac Magnetic Resonance (CMR) and compare it with Doppler derived strain and strain rate (SR) imaging in patients with repaired tetralogy of fallot( TOF).

\section{Methods}

34 patients (14 women, mean age $=21 \pm 4.1$ years) late after total correction of tetralogy of Fallot were evaluated. Absolute values of peak systolic strain and strain rate (SR) in the basal, mid, and apical segments of the RV free wall were measured and each segment and mean of three segments were compared with RV ejection fraction measured by CMR.

\section{Results}

RV function measured by CMR was negatively correlated with peak systolic strain of mid RV free wall $(\mathrm{P}=0.038$, Pearson $\mathrm{r}=-0.357)$ and also negatively correlated to both mean of strain ( $\mathrm{P}=0.028$, Pearson $\mathrm{r}=-0.376)$ and SR $(\mathrm{P}=0.035$, Spearman's rho $=-0.362)$ of basal , mid and apical segments of RV.

Rajaei Cardiovascular Medical and Research Center, Tehran, Iran, Islamic Republic of

\section{Conclusions}

Overall, in the assessment of RV function, echocardiographic measurement of strain and SR and peak systolic strain of mid RV free wall have significant correlation with RV function measured by CMR.

Published: 2 February 2011

doi:10.1186/1532-429X-13-S1-P216

Cite this article as: Kyavar et al:: Comparison between doppler derived strain and strain rate imaging and cardiac magnetic resonance in assessing right ventricular function late after repaired tetralogy of fallot. Journal of Cardiovascular Magnetic Resonance 2011 13(Suppl 1):P216.
Submit your next manuscript to BioMed Central and take full advantage of:

- Convenient online submission

- Thorough peer review

- No space constraints or color figure charges

- Immediate publication on acceptance

- Inclusion in PubMed, CAS, Scopus and Google Scholar

- Research which is freely available for redistribution
() Biomed Central 